\title{
Article \\ Evaluation of Mass Trapping Devices for Early Seasonal Management of Ceratitis Capitata (Diptera: Tephritidae) Populations
}

\author{
Eleftheria-Maria D. Bali ${ }^{1,+}$, Cleopatra A. Moraiti ${ }^{1,+}$, Charalampos S. Ioannou ${ }^{1}$, Vasilis Mavraganis ${ }^{2}$ \\ and Nikos T. Papadopoulos $1, *$ (D)
}

1 Laboratory of Entomology \& Agricultural Zoology, Department of Agriculture Crop Production and Rural Environment, School of Agricultural Sciences, University of Thessaly, 38446 Volos, Greece; elmabali@yahoo.gr (E.-M.D.B.); cmoraiti@gmail.com (C.A.M.); ioannoubabis@yahoo.com (C.S.I.)

2 HAO-DEMETER, Institute of Soil and Water Resources, Lykovrissi S. Venizelou 1, 14123 Athens, Greece; mavrag1a@otenet.gr

* Correspondence: nikopap@uth.gr

$\dagger$ Equal contribution.

check for updates

Citation: Bali, E.-M.D.; Moraiti, C.A.; Ioannou, C.S.; Mavraganis, V.; Papadopoulos, N.T. Evaluation of Mass Trapping Devices for Early Seasonal Management of Ceratitis Capitata (Diptera: Tephritidae)

Populations. Agronomy 2021, 11, 1101. https: / / doi.org/10.3390/ agronomy11061101

Received: 7 May 2021

Accepted: 25 May 2021

Published: 28 May 2021

Publisher's Note: MDPI stays neutral with regard to jurisdictional claims in published maps and institutional affiliations.

Copyright: (c) 2021 by the authors. Licensee MDPI, Basel, Switzerland. This article is an open access article distributed under the terms and conditions of the Creative Commons Attribution (CC BY) license (https:// creativecommons.org/licenses/by/ $4.0 /)$.

\begin{abstract}
Mass trapping is an environmentally safe alternative to insecticide application for the Mediterranean fruit fly management. The selection of effective trap-attractant combinations for monitoring and mass trapping control remains challenging. The current study explored the attractiveness of trapping devices during spring (early season) and summer (late season) in field cage trials. Five trapping devices were assessed: (a) the commercially available Decis ${ }^{\circledR}$ trap, (b) Tephri trap baited with Biodelear, (c) Tephri trap baited with BioLure, (d) International Pheromone McPhail trap (IPMT) baited with Biodelear, and (e) IPMT baited with BioLure. On a test day, 100 adults (50 males and 50 females) were released in each field cage wherein traps were placed individually. Trap captures were recorded at hourly intervals from 10:30 am to 5:30 pm. Our results showed that Tephri traps baited either with BioLure or Biodelear captured the most adults under low temperatures. Efficacy of Tephri traps baited with BioLure were higher than that of other trap-attractant combinations at high temperatures. Adult captures in Decis ${ }^{\circledR}$ trap were low during both seasons. More males than females were captured at low temperatures. Both efficacy and female selectivity of trapping devices are related to prevailing temperature regimes during spring and summer under semi-field conditions.
\end{abstract}

Keywords: attractiveness; captures; field cages; medfly; OFF-Season detection; traps

\section{Introduction}

The Mediterranean fruit fly (medfly), Ceratitis capitata (Wiedemann) (Diptera: Tephritidae) is a widely distributed pest that attacks numerous fruit and vegetables crops causing high yield losses [1,2]. Broad-spectrum insecticides (mainly organophosphates) applied either as bait or cover sprays have been extensively used to manage medfly populations for decades. However, most of them have been banned in the European Union (EU) due to environmental and public health concerns [3]. In recent years, novel control techniques, such as attract-and-kill approaches, have been developed and tested against fruit flies to reduce the dependency on insecticides [4-7]. Field trials revealed that they can either be as effective as conventional control method or should be used in combination with them, particularly when population density is high $[3,8,9]$. When insects are not retained in or on a device, the attract-and-kill method is called "lure-and-kill", while when a trap type that retains the target species is used, it is referred to as mass trapping [3]. Hence, the need for wide application and dispersion of synthetic insecticides is dramatically reduced following the attract-and-kill approaches, especially mass trapping. Bait stations that include the combination of an attractant and a toxic surface that kill, sterilize or infect the target insects with microorganisms are the most common lure-and-kill tools considered 
for fruit flies. In general, bait stations are more cost effective for controlling fruit flies in relation to mass trapping. This is mostly because there is no need for regular service as in the case of traps. On the other hand, one of the main advantages of mass trapping compared to other control methods is the direct "assessment" of efficacy. Trapped fruit flies can be spotted and even counted to confirm the effectiveness of the method or to follow the population trends. When bait stations or insecticide applications are employed, efficacy can be only indirectly assessed using population monitoring traps or fruit sampling to determine infestation levels [10]. Moreover, mass trapping may provide vital information regarding pest intrusion from surrounding areas and/or the existence of hot spots inside the area of interest allowing the local adjustment of traps density for better efficacy.

Mass trapping may become a very effective tool for fruit fly control, especially for species that food attractants with long lasting performance under field conditions exist. Food-based lures primarily mimic nitrogen sources that provide the protein needed by adults to attain sexual maturity and realize the full potential of reproductive performance [11]. Given that females have higher needs for protein acquisition than males for eggs development [12], attraction to food lures tend to be female-biased. Extensive efforts during the 1990s, coordinated by the International Atomic Energy Agency, resulted to the development of a three component (i.e., ammonium acetate, putrescine (1,4- diaminobutane) and trimethylamine) synthetic lure (BioLure) that has been established as the standard, commercially available attractant for both monitoring and mass trapping of medfly [10,13-15]. Although earlier field trials refer to the standard 3-component BioLure dispenser, the equivalency of Unipack to the 3-C BioLure in terms of efficacy and female selectivity has been confirmed [16-19]. Recent field experiments revealed very encouraging results on medfly mass trapping with the novel attractant Biodelear (http:/ / www.biodelear.gr, date: 5 May 2021). Biodelear is a patented, female specific lure produced by the Maillard reaction of fructose, urea and water at a ratio of 3:1:1 w/w/w [20,21]. Contrary to the BioLure that contains harmful components, such as putrescine, associated with potential toxicity to mammals [22,23], Biodelear is a non-toxic product and, therefore, more friendly to users and the environment. Moreover, the extremely low cost of the raw materials used for the synthesis of the Biodelear makes it a very promising lure for mass trapping that may be considered by developing countries as well.

The efficacy of mass trapping may be affected by a series of factors, including trap type and attractant, deployment density, pest pressure, the crop growing practices followed, geographical isolation of treated orchards, and the prevailing weather conditions $[7,10,24,25]$. Defining the optimal trap type and fly attractant is an endless task. For many decades there is a continuous effort to develop more effective, selective, inexpensive, and easier to handle combinations of traps and attractants. On the other hand, there is an increasing need to harmonize these efforts and generate comparable data that can be widely accepted and applied. Therefore, the use of commercially common traps and attractants is an important step on this direction. As far as medfly mass trapping is concerned, even small modifications on traps configuration provided with the same attractant (e.g.,BioLure) may affect capture rates up to three-fold as a result of reduced escape rates of attracted flies and the release of the proper proportions of the attractants [17]. Moreover, for the same combinations of traps and attractants, the retention/killing approach (wet or dry traps with the addition of insecticides as the killing agent) may significantly affect the performance of trapping devices under field conditions [15]. Therefore, studies aiming to compare the efficacy of specific attractants, especially of novel ones, should consider all these factors to draw safe conclusions.

Attract-and-kill approaches, including both bait stations and mass trapping techniques, have been successfully applied as alternatives to the conventional control of medfly populations in highly susceptible crops [7,8,26-28]. The common practice in these cases is the "on-season" management of pest populations that refers to the establishment of the control devices (bait stations/traps) just before fruits become susceptible to medfly attacks. A major drawback of this approach, especially in temperate regions, is the fact that usually 
at this point, the medfly has already built up high population densities, making their control more difficult and less cost effective with mass trapping. The establishment of the mass trapping grid early in the season (spring) targeting low medfly population densities may provide an alternative, promising approach. The approach is called "off-season" management of insect pests and targets the population growth over a longer period of time and well before the ripening season arrives. Under this scheme, it is anticipated that less effort in terms of labor and trap density will be necessary for population suppression. However, limited information exists regarding the performance of trapping devices for "off-season" control under relatively low population densities that may be coupled with limited adult flight activity and dispersion [2,29]. The "off-season" application often in temperate areas coincides with non-optimal conditions for medfly population growth (i.e., low temperatures). However, there is limited information about the performance of different mass trapping devices under various temperature conditions, which may affect both the activity and behavior of adults as well as the performance of attractants.

Considering the importance of the mass trapping technique for medfly control and the existing knowledge gaps for its "off-season" application, the main objective of the current study was to examine the effectiveness of common, commercially available trapping devices baited with two types of female attractants at two seasonal temperature regimes. In particular, the performance of the different trapping devices was tested in field cages early in the spring under sub-optimal temperatures for medfly activity and during summer under optimal temperature conditions. The importance of seasonal performance of different trapping devices is discussed.

\section{Materials and Methods}

\subsection{Insects and Field Cages}

All flies used were "wildish" (F4, F5 laboratory generation from field infested fruits). To establish the laboratory colony, field infested citrus fruits were collected from the area of Volos (Magnesia, Greece) and transferred to the Laboratory of Entomology and Agricultural Zoology at the University of Thessaly where larvae completed development and pupated under constant laboratory conditions (temperature: $25 \pm 2{ }^{\circ} \mathrm{C}$ and RH: $55 \pm 5 \%$ 14L:10D). Pupae were collected twice a week and placed in wooden framed, wire-screened cages $\left(30 \times 30 \times 30 \mathrm{~cm}^{3}\right)$ to allow adults to emerge. Upon emergence, adults had ad libitum access to water and a standard adult diet consisting of sugar, yeast hydrolysate and water at a ratio of 4:1:5. Females had access to oviposit into artificial oviposition substrates, consisted of a red, plastic, hollow hemisphere $5 \mathrm{~cm}$ in diameter with 50 evenly distributed holes (diameter $0.7 \mathrm{~mm}$ ) through which females laid their eggs. The base of each hemisphere was fitted into a $5 \mathrm{~cm}$ in diameter hole performed on the cover of a plastic, $5.5 \mathrm{~cm}$ in diameter Petri dish. A plastic cup with $0.5 \mathrm{~mL}$ of orange juice was placed in the base of the Petri dish to stimulate oviposition. Eggs were collected from the inner surface of the dome, and larvae were reared on a standard artificial diet [30].

Trapping trials were performed using five cylindrical ( $2.9 \mathrm{~m}$ diameter $\times 2 \mathrm{~m}$ height $)$ plastic-screen field cages housing one potted citrus or olive tree each $(\sim 1.80 \mathrm{~m}$ height and $1.3 \mathrm{~m}$ canopy diameter). Fruits, if any, were removed from the trees. Field cages were protected from the direct sunlight by placing a shading net one meter above their top.

\subsection{Trapping Devices}

The following five trapping devices were assessed: (a) Decis ${ }^{\circledR}$ trap, (b) Tephri trap baited with Biodelear, (c) Tephri trap baited with BioLure, (d) the International Pheromone McPhail trap (IPMT) baited with Biodelear, and (e) IPMT baited with BioLure. The commercially available, ready-to-use Decis ${ }^{\circledR}$ trap (Bayer CropScience, International, Monheim am Rhein, Germany) is a dry trap consisted of a top part, which is colorless, transparent and internally impregnated with a pyrethroid insecticide ( $0.015 \mathrm{~g}$ deltamethrin/dispenser) as a killing agent. The lower part is rather orange with four lateral holes $(2 \mathrm{~cm}$ each) that serve as entrance to the trap. A mixture of $7.8 \mathrm{~g}$ ammonium acetate, $0.5 \mathrm{~g}$ chlorohydrate 
trimethylamine and $0.03 \mathrm{~g} 1.5$ diamineopentane is used as attractant in Decis ${ }^{\circledR}$ trap. The Tephri trap (Agro Alcoy, Alcoy, Spain) is consisted of an $11 \mathrm{~cm}$ deep, yellow, invaginated base covered with a $3.5 \mathrm{~cm}$ in high opaque lid. The diameter at the junction of lid and base is $12 \mathrm{~cm}$. In addition to the bottom opening ( $3 \mathrm{~cm}$ diameter), the Tephri trap has four lateral openings of $2.1 \mathrm{~cm}$ in diameter each, being $4 \mathrm{~cm}$ from trap top. The plastic International Pheromone's McPhail trap (IPMT) has a $7 \mathrm{~cm}$ tall yellow base with a $4.5 \mathrm{~cm}$ diameter, funnel-like opening and a $12 \mathrm{~cm}$ tall clear top. The trap is $17 \mathrm{~cm}$ in diameter at its widest point (International Pheromone Systems Limited, South Wirral, England).

The female-specific attractants, BioLure and Biodelear, were used in both IPMT and Tephri traps. The BioLure (Unipack by Suterra) is a three-component food lure consisting of a mixture of $29.8 \%$ ammonium acetate, $12.4 \%$ trimethylamine hydrochloride and $0.2 \%$ 1,4- Diaminobutane. Biodelear as mentioned previously, is an innovative, environmentally friendly female attractant in liquid form with high viscosity. BioLure was properly placed in the IPMT trap by attaching the dispenser with paper tape on the inner walls of the transparent part of the trap. In the Tephri trap, BioLure was placed at the top of the device. Custom-made dispensers, consisting of pieces of Wettex sponge wrapped and placed in rolls tightly closed in a piece of sieve, were used for applying Biodelear attractant into the traps. The Wettex rolls were soaked in liquid Biodelear and allowed to drain under ambient conditions before being used. Each dispenser was impregnated with $17 \mathrm{~g}$ liquid Biodelear. In the Tephri trap, the Biodelear dispenser was placed in the existing basket. In the IPMT trap, the dispenser was hung from the trap ceiling with a short piece of wire. In both IPMT and Tephri traps, $250 \mathrm{~mL}$ of water with 1\% detergent as surfactant agent was used to capture and retain the attracted flies.

\subsection{Experimental Procedure}

Field cage trials were conducted from 29 March to 14 April 2020 (spring season) and from 6 to 26 July 2020 (summer season) in the outdoor facilities of the Laboratory of Entomology and Agricultural Zoology in Volos area (Magnesia, Greece).

Two days before adult emergence, pupae were transferred from the standard laboratory conditions to ambient conditions of a non-heated warehouse until adult emergence. Upon emergence, adults were placed in wooden cages with ad libitum access to adult food (sugar: yeast in ratio 4:1) and water. Two days before conducting an experimental trial, adults were sexed and placed in groups of 50 individuals (males or females) into Plexiglas, wire-screened cages $\left(20 \times 20 \times 20 \mathrm{~cm}^{3}\right)$ with ad libitum assess to water and granulated sugar.

At test day (9:00 a,m.), 50 females and 50 males (10-15 days old) were released into each field cage. Thirty minutes later, the respective mass trapping devices were placed in the field cages. A single trapping device was placed in each field cage at $1.7 \mathrm{~m}$ height, in the southwestern side of the canopy of each potted tree. Flies had ad libitum access to non -proteinaceous food source (drops of sugar syrup) and water (water-soaked cotton pads fastened to tree branches). Trap captures (number of males and females entering the trap) were recorded and removed at hourly intervals from 10:30 a.m. to 5:30 p.m. (8 records/replication). To do so, each mass trapping device was placed into a plastic bag that sealed to avoid escape of captured flies and replaced with a new one of the same type. The experiment was repeated 10 times (trial days). Trapping devices were rotated within field cages in a clockwise manner per replication. The temperature was hourly recorded using an analog thermometer, placed near to the field cage arena in each replication. Data for daily relative humidity were obtained from the meteorological station of Volos city located $3 \mathrm{~km}$ away from the experimental area (https://stratus.meteo.noa.gr/, date: 10 August 2020).

In case of dead flies found within the field cage arena, they were replaced with new ones of the same cohort before the next record. 


\subsection{Statistical Analysis}

The Kolmogorov-Smirnov test was used to assess the normality of data distributions. Generalized Linear Models (GLMs) with Poisson loglinear distribution was used to determine the effects of treatment (mass trapping device), sex, temperature and their interactions (excluding that of treatment * sex $^{*}$ temperature) on adult captures in each experimental day. Given that the interaction between treatment and temperature on adult captures was significant $(p<0.001)$ (see "Results" section), we explored the effects of treatment and sex, and their interaction on adult captures for each season using the GLMs with Poisson loglinear distribution. The Bonferroni test was carried out to adjust for multiple comparisons at $\alpha=0.05$. To assess the relationship between temperature and adult captures (males and females) quadratic regression analysis was performed. The proportion of female captures was estimated by dividing the total female captures by the sum of males and females captured. One-Way ANOVA followed by the Tukey HSD test for multiple comparisons was used to determine the effect of treatment on the proportion of female captured in spring and summer trials. All analyses were performed using SPSS v.26.0 (SPSS Inc., Chicago, IL, USA).

\section{Results}

\subsection{Climatic Data}

The average temperature inside the field cages ranged from 11 to $21.9^{\circ} \mathrm{C}$ and from 26.4 to $33.5^{\circ} \mathrm{C}$ during the spring and summer experimental trials, respectively. The absolute minimum and maximum temperature ranged from 11 to $19^{\circ} \mathrm{C}$ and 14 to $24^{\circ} \mathrm{C}$, respectively in spring trials, while in the summer trials it the range was from 25 to $31^{\circ} \mathrm{C}$ and 29 to $36^{\circ} \mathrm{C}$, respectively (Figure 1). The mean daily relative humidity ranged from 40 to $70 \%$ in both seasons.
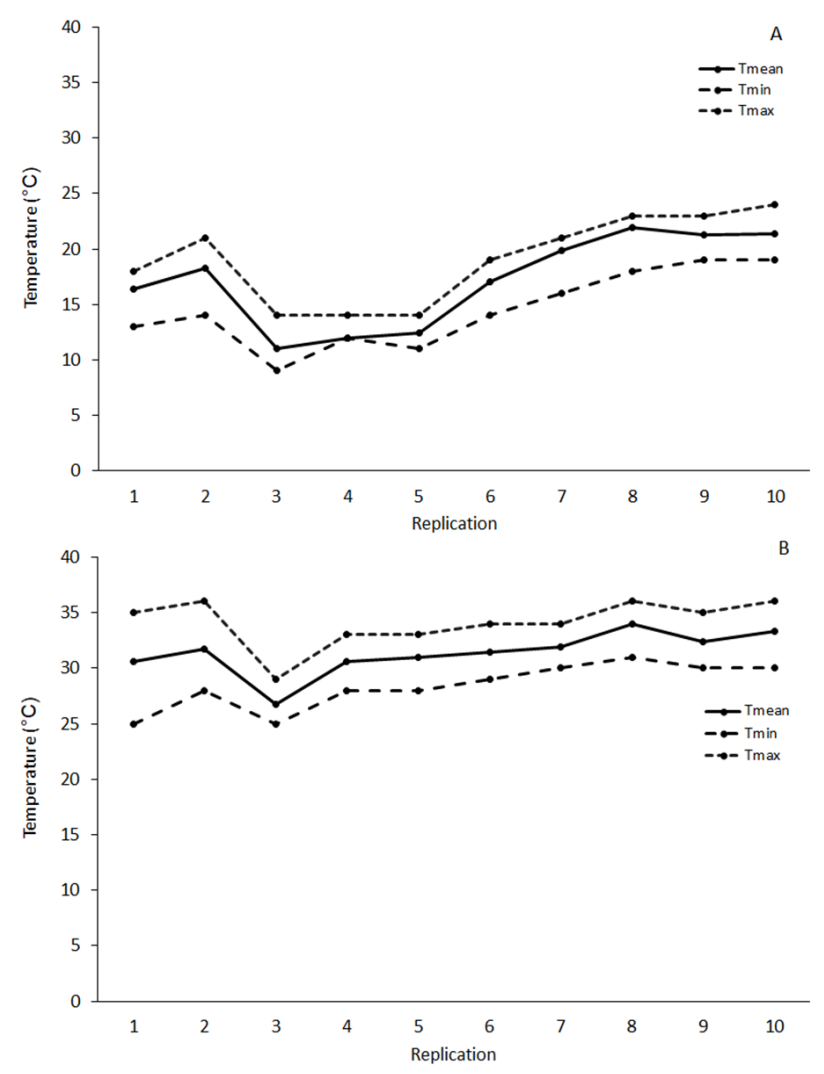

Figure 1. Mean (Tmean), minimum (Tmin) and maximum (Tmax) temperatures during spring (A) and summer (B) field cage trials. Tmean was calculated as the mean temperature of the eight hourly records in each test date (replication) using an analog thermometer. 


\subsection{Efficacy and Female Selectivity of Trapping Devices}

The GLMs model reveals trapping device, temperature and sex as significant predictors of adult captures (Table 1). The significant interaction between the trapping device and temperature highlights the importance of the season for the performance of the different mass trapping devices. (Table 1) Likewise, the significant interaction of sex by temperature indicates the differential response of males and females to different temperatures. At lower temperatures, captures were more skewed towards males than at higher temperatures (Figure 2). On the other hand, both males and females appear to respond equally among the different trapping devices as the interaction between these two parameters was not significant (Table 1).

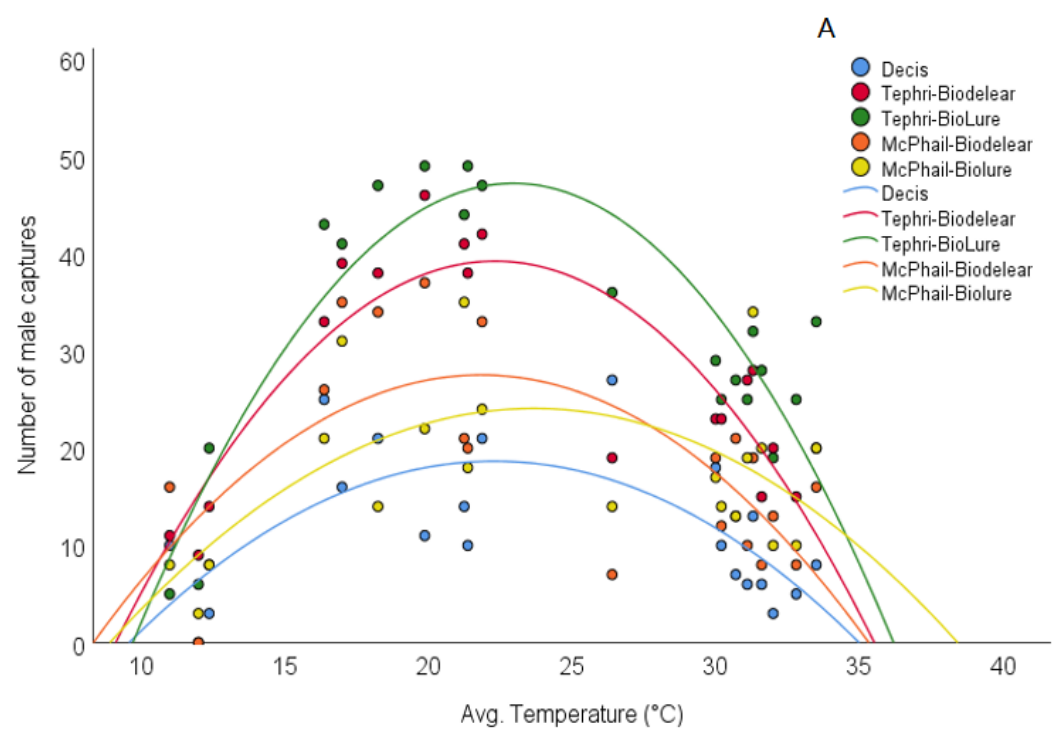

B

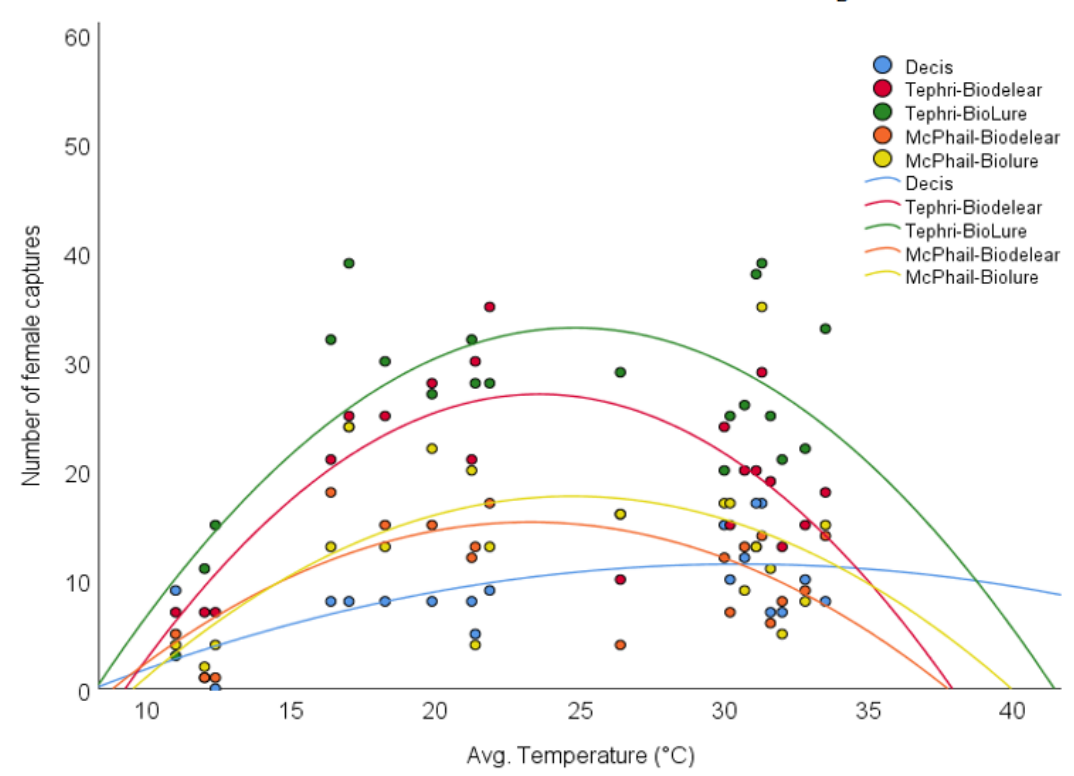

Figure 2. Relationship between male (A) and female (B) captures and average temperatures. For males (A) Decis ${ }^{\circledR}: \mathrm{y}=-0.12 \mathrm{x}^{2}+5.16 \mathrm{x}-38.8, \mathrm{R}^{2}=0.448, p=0.006$; Tephri-Biodelear: $\mathrm{y}=-0.23 \mathrm{x}^{2}+$ 10.05x $-72.95, \mathrm{R}^{2}=0.71, p<0.001$; Tephri-BioLure: $\mathrm{y}=-0.27 \mathrm{x}^{2}+12.38 \mathrm{x}-94.85, \mathrm{R}^{2}=0.777, p<0.001$; IPMT-Biodelear: $\mathrm{y}=-0.15 \mathrm{x}^{2}+6.6 \mathrm{x}-44.56, \mathrm{R}^{2}=0.435, p=0.008$ and IPMT-BioLure: $\mathrm{y}=-0.11 \mathrm{x}^{2}+$ $5.24 \mathrm{x}-37.9, \mathrm{R}^{2}=0.333, p=0.032$. For females (B) Decis ${ }^{\circledR}: \mathrm{y}=-0.02 \mathrm{x}^{2}+1.39 \mathrm{x}-9.84, \mathrm{R}^{2}=0.398$, $p=0.013$; Tephri-Biodelear: $\mathrm{y}=-0.13 \mathrm{x}^{2}+6.21 \mathrm{x}-46.17, \mathrm{R}^{2}=0.526, p=0.002$; Tephri-BioLure: $\mathrm{y}=-0.12 \mathrm{x}^{2}+5.97 \mathrm{x}-41, \mathrm{R}^{2}=0.484, p=0.004$; IPMT-Biodelear: $\mathrm{y}=-0.07 \mathrm{x}^{2}+3.4 \mathrm{x}-24.32, \mathrm{R}^{2}=0.293$, $p=0.052$, and IPMT-BioLure: $\mathbf{y}=-0.08 \mathrm{x}^{2}+3.77 \mathrm{x}-29.02, \mathrm{R}^{2}=0.398, p=0.097$. 
Table 1. Results of the GLMs on the effects of the trapping device, sex, temperature and all two way interactions on adult captures in the field cage trials during both spring and summer season.

\begin{tabular}{cccc}
\hline Parameter & $\chi^{2}$ & df & $p$-Value \\
\hline Trapping device & 311.744 & 4 & $<0.001$ \\
Sex & 48.695 & 1 & $<0.001$ \\
Temperature & 343.571 & 19 & $<0.001$ \\
Trapping device $\times$ Sex & 7.671 & 4 & 0.104 \\
Trapping device $\times$ Temperature & 184.991 & 76 & $<0.001$ \\
Sex $\times$ Temperature & 48.827 & 19 & $<0.001$ \\
\hline
\end{tabular}

Considering the data from each season, average adult captures (males and females) in spring trials ranged from $19.5 \pm 3.4$ to $59.6 \pm 8.9$ adults and in summer trials from $22.2 \pm 3.2$ to $55.7 \pm 3.2$ adults in Decis ${ }^{\circledR}$ and Tephri traps baited with BioLure, respectively (Table 2). Figure 3 gives the male and female captures for each trapping device during spring and summer trials. The distribution range of capture values for both males and females was wider in the spring trials compared to the summer ones. Additionally, an increased number of females responded to traps during summer regardless of the trapping device. The graph also depicts the higher performance of the Tephri tap baited with BioLure and the lower of the Decis ${ }^{\circledR}$ trap.
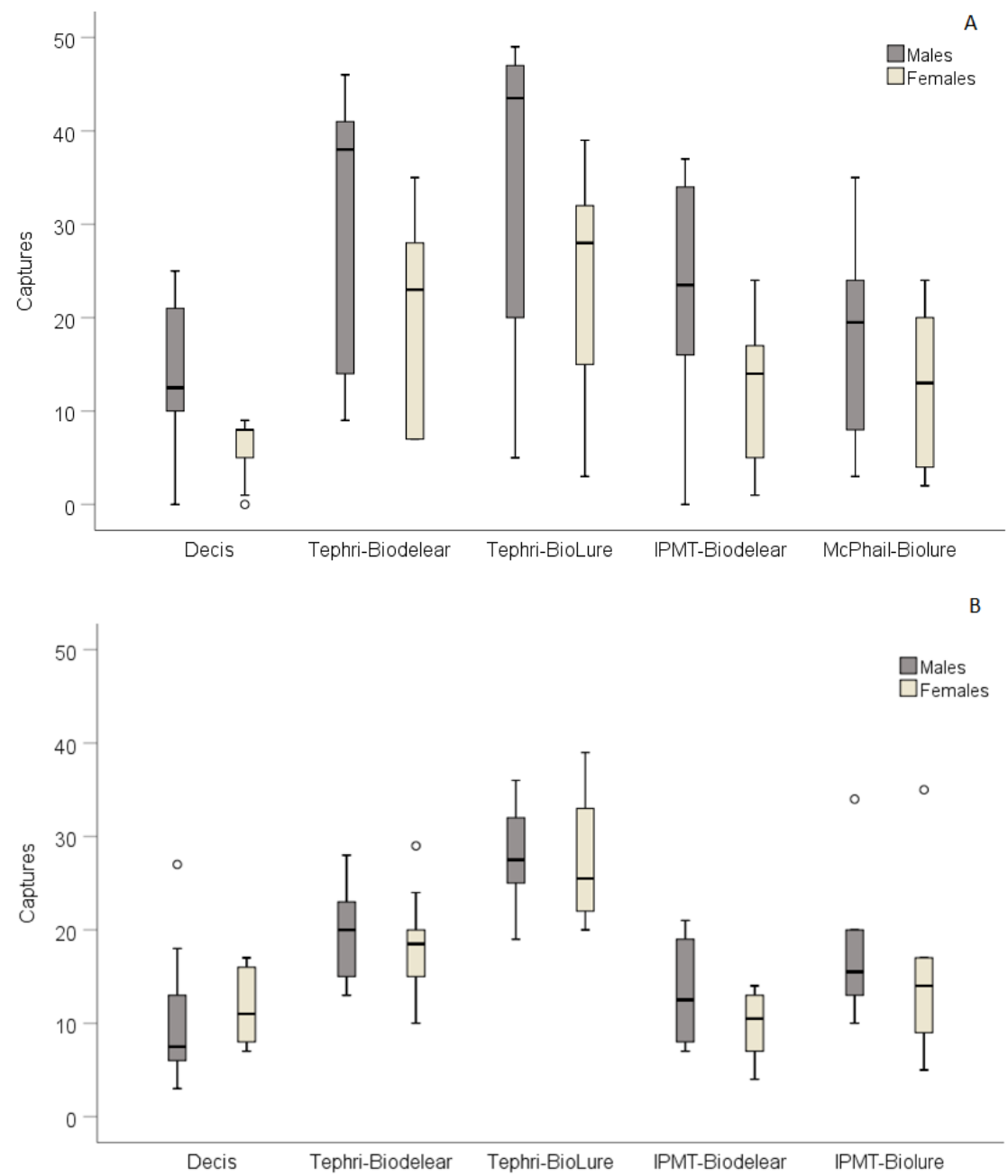

Figure 3. Box plots depicting the percentage of males and females caught in the five mass trapping devices in the field cages trials conducted during spring (A) and summer (B). A total of 50 males and 50 females were released in each field cage. 
Table 2. Captures of adults (both males and females) and the proportion of females in the five mass trapping devices during the spring and summer trials in the field cages. Ten replicates (different experimental dates) were run in each season. A total of 50 males and 50 females were released in each field cage.

\begin{tabular}{ccccc}
\hline Trapping Device & \multicolumn{2}{c}{ Average Number of Adult Captures $\pm \mathbf{S E}^{\mathbf{a}}$} & Average Proportion of Females (Females/(Males + Females) $^{\mathbf{b}}$ \\
\hline & Spring & Summer & Spring & Summer \\
Decis & $19.5 \pm 3.4^{\mathrm{c}}$ & $22.2 \pm 3.2^{\mathrm{c}}$ & $0.37 \pm 0.08^{\mathrm{a}}$ & $0.57 \pm 0.04^{\mathrm{a}}$ \\
Tephri-Biodelear $^{\mathrm{c}}$ & $51.7 \pm 7.6^{\mathrm{a}}$ & $38.6 \pm 2.8^{\mathrm{b}}$ & $0.40 \pm 0.01^{\mathrm{a}}$ & $0.47 \pm 0.033^{\mathrm{ab}}$ \\
Tephri-BioLure & $59.6 \pm 8.9^{\mathrm{a}}$ & $55.7 \pm 3.2^{\mathrm{a}}$ & $0.43 \pm 0.03^{\mathrm{a}}$ & $0.50 \pm 0.02^{\mathrm{ab}}$ \\
IPMT-Biodelear $^{\mathrm{b}}$ & $35.1 \pm 6.2^{\mathrm{b}}$ & $23.3 \pm 2.6^{\mathrm{c}}$ & $0.39 \pm 0.07^{\mathrm{a}}$ & $0.43 \pm 0.02^{\mathrm{b}}$ \\
IPMT-BioLure & $30.3 \pm 5.6^{\mathrm{b}}$ & $31.7 \pm 4.7^{\mathrm{b}}$ & $0.38 \pm 0.03^{\mathrm{a}}$ & $0.45 \pm 0.02^{\mathrm{b}}$ \\
\hline
\end{tabular}

${ }^{a}$ In the same column, means followed by the same letter are not significantly different (Bonferroni test, $\left.p<0.05\right) ;{ }^{b}$ Means followed by the same letter are not significantly different at a 5\% level in each season (Tuckey HSD test, $p<0.05$ ).

The GLMs model shows that both the trapping device $\left(\mathrm{x}^{2}=251.8, \mathrm{df}=4, p<0.001\right)$ and sex $\left(x^{2}=101.7, \mathrm{df}=1, p<0.001\right)$ were significant predictors of the adult captures during spring trials. The interaction between trapping device and sex was not significant $\left(\mathrm{x}^{2}=7.1, \mathrm{df}=4, p=0.125\right)$, suggesting similar sex ratio of the captured adults among trapping devices. Tephri traps baited with either BioLure or Biodelear captured the highest number of adults followed by the IPMT traps baited with either BioLure or Biodelear (Table 2, Bonferroni test, $p<0.05$ ). The Decis ${ }^{\circledR}$ trap captured the lowest number of adults $(p<0.05)$. For summer trials, GLMs analysis reveals trapping device as the only significant predictor of adult captures $\left(\mathrm{x}^{2}=210.5, \mathrm{df}=4, p<0.001\right)$, as opposed to sex $\left(\mathrm{x}^{2}=2.5, \mathrm{df}=1\right.$, $p=0.11)$ and their interaction $\left(\mathrm{x}^{2}=6.5, \mathrm{df}=4, p=0.164\right)$. The Tephri trap baited with BioLure outperformed all other trapping devices during summer trials, followed by Tephri trap baited with Biodelear $(p<0.05)$. The IPMT trap baited with BioLure captured higher number of adults compared to both the IPMT trap baited with Biodelear and the Decis ${ }^{\circledR}$ trap $(p<0.05)$ that captured similar number of individuals $(p>0.05)$.

The average proportion of female captures ranged from $0.37 \pm 0.08$ (Decis ${ }^{\circledR}$ ) to $0.43 \pm 0.03$ (Tephri with BioLure) (Table 2). More males than females were captured in all trapping devices during spring trials with no differences among them (ANOVA, $\left.\mathrm{F}_{4,45}=0.182, p=0.947\right)$. The proportion of female captures increased in the summer trials ranging from $0.43 \pm 0.02$ (IPMT traps baited with Biodelear) to $0.57 \pm 0.04$ (Decis ${ }^{\circledR}$ ) (Table 2). The trapping device was a significant predictor of the female proportion captures (ANOVA; $\mathrm{F}_{4,45}=4.2, p=0.006$ ). The proportion of female captured in Decis ${ }^{\circledR}$ trap were significantly higher than that in IPMT trap baited with Biodelear (Tukey HSD test, $p=0.05$ ) or BioLure (Tukey HSD, $p=0.017$ ). There was no significant difference in proportion of female captures between Tephri traps baited with each attractant (Tukey HSD test, $p=0.955$ ) as well as between IPMT traps baited with BioLure or Biodelear (Tukey HSD test, $p=0.384$ ) (Table 2).

\subsection{Relationship of Treatment Captures and Temperature for Males and Females}

Quadratic regression analysis on the effects of temperature on either male or female captures for each mass trapping device, demonstrates a peak male response at temperatures ranging from 20 to $25^{\circ} \mathrm{C}$ (Figure 2). A slight shift of female response to higher temperatures has also been revealed with optimum captures recorded at temperatures ranging from approximately 22 to $28^{\circ} \mathrm{C}$ (Figure 2). Responses of both males and females dramatically decrease at temperatures lower than $15^{\circ} \mathrm{C}$ and higher than $35^{\circ} \mathrm{C}$. The relationship between temperature and adult captures was significant $(p<0.05)$ in all cases except for female response to IPMT-BioLure $(p>0.05)$ (Figure 2$)$.

\section{Discussion}

Our results demonstrated that the performance of trapping devices differ between seasons. The Tephri traps outperformed the IPMT McPhail-type traps under the low temperatures of spring, regardless of the baited attractant. In summer trials, Tephri traps 
captured more adults when they were baited with Biolure than Bioldelear, followed by the IPMT trap baited with BioLure. It seems that the ambient temperatures in each season affect both the trap type and the attractant efficacy. Female selectivity of the five trapping devices considered in the current study is also affected by the temperatures. More males than females were captured in all trapping devices under low temperature conditions. The proportion of female captures increased during summer trials but barely exceeded that of males. Although the performance of the Decis ${ }^{\circledR}$ trap was the lowest as far as adult captures is considered, it was the most female selective at high temperatures, as opposed to IMPT traps baited with each attractant. Hence, at least under our experimental conditions, the seasonal temperature regimes affect the performance of traps and attractants as well as the sex ratio of captured medflies.

The proportion of captured adults during both spring and summer trials never exceeded the $60 \%$ of the released individuals, albeit more flies are likely to have been attracted and landed on the traps [27]. This indicates that a considerable proportion of adults do not respond even to the best existing trapping devices and under confinement in field cages. In line with a previous comparative study conducted in citrus orchards [29], Tephri traps baited with BioLure were more attractive than IPMT ones at low temperatures. In our study Tephri traps outperformed IPMT traps at higher temperatures in contrast to Katsoyannos et al. [15] and Katsoyannos and Papadopoulos [31]. The above discrepancies may be attributed to the different experimental approaches followed and to the performance of trapping devices in divergent field sites and conditions. For example, the Open Bottom Traps were more attractive for medflies in humid tropical environments than Mediterranean orchards [13]. The performance of both Tephri and IPMT traps baited with BioLure as well as that of Decis ${ }^{\circledR}$ traps was similar between spring and summer trials. In contrast, Tephri and IPMT traps baited with Biodelear were much more efficient in spring compared to summer trials. Apparently, the commercially available dispensers (e.g., BioLure) exhibit a rather controlled and constant emission rates at variable environmental conditions compared to Biodelear. Indeed, the custom-made dispensers considered for the novel attractant Biodelear do not assure any controlled release of the attractive compounds. This also indicates that development of a proper dispersion device could increase the performance of Biodelear.

Both BioLure and Biodelear perform better in Tephri than IPMT traps under both spring and summer conditions in field cage trials. It seems that the dispersion of the attractants was more efficient in Tephri traps compared to IPMT ones, at least in close range. Tephri traps, besides the typical lower, funnel-like opening of all McPhail type traps such as IPMT, include four lateral holes that serve as both emission and entrance gates. Other aspects that may contribute to the higher performance of the Tephri traps are related with visual stimuli, which are quite important for the short-range (within tree) attraction of the Mediterranean fruit fly and that of other fruit flies [32,33]. Visual stimuli related to trap type are expected to be more important in our field cage study since flies kept confined in proximity. However, the visual properties of such traps might not be equally important in field conditions. In such conditions, there is a list of other factors that affect the performance of the traps, such as the physiological and age structure of feral flies (e.g., age, mating status, feeding history), the structure of orchards as well as the prevailing environmental conditions that may affect both dispersion of odor attractants and response of adult flies. The efficacy of traps may be also related to retention method [34]. Wet traps that employ a liquid retention system (aqueous solution of propylene glycol or surfactant) like the Tephri traps used in our trials may suffer of high escape rates of the attracted individuals. On the other hand, under relatively dry environmental conditions, the humid environment within trap may facilitate emission of the attractant and hence have a synergistic contribution at low temperatures [15,29]. Dry traps bearing insecticide killing agents such as the Decis ${ }^{\circledR}$ trap are expected to have lower escape rates and high knockdown effects. Repellent properties of killing agents such as DDVP (2,2-dichlorovinyl dimethyl phosphate) have been also reported in the past [15,35]. Hence, the overall efficacy 
of the mass trapping devices involves a complex interaction between trap design, attractant combination, retention method and temperature under semi-field conditions. Results from field cage studies testing the attractiveness of different trapping devices should be carefully interpreted considering some of the limitations mentioned earlier. However, they can generate much needed information for the performance of trapping devices during periods of adverse environmental conditions, when fruit fly populations are extremely low in field conditions like the winter/spring period in temperate areas [2].

Even though the proportion of female captures remain low $(<60 \%)$, female selectivity of mass trapping devices was significantly affected by temperature. Under low temperatures, adult captures were male biased in all mass trapping devices, supporting previous results for a similar response of medfly to BioLure regardless of trap type (Tephri or IPMT), [29]. For BioLure-baited traps, the female selectivity remained high ( $>70 \%)$ and similar between McPhail type and Tephri traps in deciduous orchards of West Australia during summer [36]. The proportion of female captures in IPMT traps baited with BioLure was higher than that of males throughout the season in earlier detection studies in deciduous fruit orchards [2]. In field, seasonal patterns of female captures are aligned with the presence of ripe or ripening host fruits. Females are often "clustered" around host trees bearing fruits, as opposed to males which are more randomly dispersed across orchards and the fruiting season [2,37-39]. Mated females are more likely to be attracted to traps that mimic the shape, size, and color of host fruits when searching for mates and oviposition sites $[32,40]$. Whether the visual properties of the traps account for the variability in the proportion of female captures in our summer trials (e.g., higher performance of the Decis ${ }^{\circledR}$ traps) needs to be further explored. It is well demonstrated that female medflies respond strongly to yellow traps (such as IPMT and Tephri traps) [32], and sphere-like objects (such as the orange Decis ${ }^{\circledR}$ trap) $[31,33,41,42]$. For increasing female selectivity, female-targeted traps are suggested to be placed on or near host trees bearing ripe or semi-ripe fruits [43]. Hence, along with the trap type, the presence of ripe or ripening host fruits (early maturing or not) may be crucial for female captures under different temperature conditions, and related field verification studies are needed.

Low medfly populations remain a prerequisite for success of mass trapping control in deciduous fruit orchards $[25,44,45]$, underlying the need for both timely detection of small population and the use of efficient trap-attractant combinations for mass trapping control. Trimedlure-based traps are used worldwide for early detection purposes based on their species specificity and their effectiveness under low temperature and low population conditions $[29,46]$. Males were caught earlier in male lure-based traps than females in food-based traps [19,29,36], although exceptions exist [2,13,14,37]. Inclusion in medfly monitoring networks of food-based lures that capture both females and males will increase the probability of precisely detecting medfly $[19,29]$, excluding in any case any potential negative interactions between traps when placed in proximity [47]. Our results that adult captures were higher in Tephri traps baited either with BioLure or Biodelear at low temperatures, highlighting the potential of both Tephri combinations to be used for early detection purposes. In line with our results, Miranda et al. [29] proposed Tephi traps baited with BioLure for monitoring wild female medfly populations under low temperatures. The same combination of traps and attractants could be considered to target low medfly populations for mass trapping purposes early in the season and under low temperature conditions. On the other hand, female selectivity of mass trapping devices is also equally important for success of mass trapping control since maximum number of females need to be removed from field populations before attacking fruits [48]. The low female selectivity of all trapping devices tested under low temperature conditions should be considered in early season mass trapping efforts. Nevertheless, the efficacy of mass trapping to control medfly populations might remain high since very low populations are targeted. Considering also the efficacy of mass trapping devices [17], Tephri traps baited with BioLure as a first choice and Tephri traps baited with Biodelear as a second choice could be used for mass trapping control at higher temperatures. Under such conditions, the female selectivity 
in the "ready-to-use" Decis ${ }^{\circledR}$ trap was substantially higher compared to that of Tephri and IPMT traps, but the low numbers of total captures are a matter of concern. Along with the extensively reported superior performance of BioLure for suppressing medfly populations at high temperatures $[17,24,31,39,49]$, our results indicate also the promising choice of Biodelear in Tephri trap, instead the IPMT trap as previously selected for pilot trials [21].

\section{Conclusions}

The selection of effective trap-lure combinations for monitoring and mass trapping control of medfly populations especially early in the season and under low population densities remain challenging. In this study, we showed that both efficacy and female selectivity of mass trapping devices are related to prevailing temperatures during spring and summer seasons under semi-field conditions. However, the field cage trials provide an approximation of the performance of trap-attractant combinations $[50,51]$ and, consequently, the field verification of the most promising mass trapping devices should be conducted.

Author Contributions: Conceptualization, N.T.P., E.-M.D.B., C.A.M.; methodology, N.T.P. and E.M.D.B., C.S.I.; formal analysis, N.T.P. and C.A.M., C.S.I.; investigation, N.T.P., E.-M.D.B., C.A.M.; resources, N.T.P., V.M.; data curation, E.-M.D.B., C.A.M.; writing—original draft preparation, N.T.P., E.-M.D.B., C.A.M.; writing-review and editing, N.T.P., E.-M.D.B., C.A.M., C.S.I., V.M.; visualization, N.T.P., C.A.M.; supervision, N.T.P.; project administration, N.T.P.; funding acquisition, N.T.P. All authors have read and agreed to the published version of the manuscript.

Funding: This research was funded by the FF-IPM Project (HORIZON 2020, GA818184).

Institutional Review Board Statement: Not applicable.

Informed Consent Statement: Not applicable.

Data Availability Statement: The datasets used or analyzed during the current study, are available upon request, from the FF-IPM project.

Acknowledgments: We would like to thank Paraschos Prekas for technical support and the project "Life Biodelear" for providing the novel attractant Biodelear.

Conflicts of Interest: The authors declare no conflict of interest. The funders had no role in the design of the study; in the collection, analyses, or interpretation of data; in the writing of the manuscript, or in the decision to publish the results.

\section{References}

1. Liquido, N.J.; Cunningham, R.; Shinoda, L. Host Plants of the Mediterranean Fruit Fly, Diptera: Tephritidae, an Annotated World Review; Miscellaneous Publications of the Entomological Society of America: Annapolis, MD, USA, 1991; Volume 77, pp. 1-52.

2. Papadopoulos, N.T.; Katsoyannos, B.I.; Kouloussis, N.A.; Hendrichs, J.; Carey, J.R.; Heath, R.R. Early detection and population monitoring of Ceratitis capitata (Diptera: Tephritidae) in a mixed-fruit orchard in northern Greece. J. Econ. Entomol. 2001, 94, 971-978. [CrossRef]

3. Navarro-Llopis, V.; Primo, J.; Vacas, S. Efficacy of attract-and-kill devices for the control of Ceratitis capitata. Pest Manag. Sci. 2013, 69, 478-482. [CrossRef]

4. $\quad$ Dias, N.P.; Zotti, M.J.; Montoya, P.; Carvalho, I.R.; Nava, D.E. Fruit fly management research: A systematic review of monitoring and control tactics in the world. Crop Prot. 2018, 112, 187-200. [CrossRef]

5. Gregg, P.C.; Del Socorro, A.P.; Landolt, P.J. Advances in attract-and-kill for agricultural pests: Beyond pheromones. Annu. Rev. Entomol. 2018, 63, 453-470. [CrossRef]

6. Rachid, E.; Ahmed, M. Cur Tephritidae) control in Morocco. J. Entomol. 2018, 15, 47. [CrossRef]

7. Hafsi, A.; Rahmouni, R.; Ben Othman, S.; Abbes, K.; Elimem, M.; Chermiti, B. Mass trapping and bait station techniques as alternative methods for IPM of Ceratitis capitata Wiedmann (Diptera: Tephritidae) in citrus orchards. Orient. Insects 2020, 54, 285-298. [CrossRef]

8. Hafsi, A.; Abbes, K.; Harbi, A.; Rahmouni, R.; Chermiti, B. Comparative efficacy of Malathion and spinosad bait sprays against Ceratitis capitata Wiedmann (Diptera: Tephritidae) in Tunisian citrus orchards. J. Entomol. Zool. Stud. 2015, 3, $246-249$.

9. Rahman, T.; Broughton, S. Suppressing Mediterranean fruit fly (Diptera: Tephritidae) with an attract-and-kill device in pome and stone fruit orchards in Western Australia. Crop Prot. 2016, 80, 108-117. [CrossRef] 
10. Navarro-Llopis, V.; Vacas, S. Mass trapping for fruit fly control. In Trapping and the Detection, Control, and Regulation of Tephritid Fruit Flies; Springer: Berlin/Heidelberg, Germany, 2014; pp. 513-555.

11. Christenson, L.; Foote, R.H. Biology of fruit flies. Annu. Rev. Entomol. 1960, 5, 171-192. [CrossRef]

12. Kouloussis, N.A.; Damos, P.T.; Ioannou, C.S.; Tsitsoulas, C.; Papadopoulos, N.T.; Nestel, D.; Koveos, D.S. Age related assessment of sugar and protein intake of Ceratitis capitata in ad libitum conditions and modeling its relation to reproduction. Front. Physiol. 2017, 8, 271. [CrossRef] [PubMed]

13. Epsky, N.; Hendrichs, J.; Katsoyannos, B.; Vasquez, L.; Ros, J.; Zümreoglu, A.; Pereira, R.; Bakri, A.; Seewooruthun, S.; Heath, R. Field evaluation of female-targeted trapping systems for Ceratitis capitata (Diptera: Tephritidae) in seven countries. J. Econ. Entomol. 1999, 92, 156-164. [CrossRef]

14. Katsoyannos, B.I.; Heath, R.R.; Papadopoulos, N.T.; Epsky, N.D.; Hendrichs, J. Field evaluation of Mediterranean fruit fly (Diptera: Tephritidae) female selective attractants for use in monitoring programs. J. Econ. Entomol. 1999, 92, 583-589. [CrossRef]

15. Katsoyannos, B.; Papadopoulos, N.; Heath, R.; Hendrichs, J.; Kouloussis, N. Evaluation of synthetic food-based attractants for female Mediterranean fruit flies (Dipt., Tephritidae) in McPhail type traps. J. Appl. Entomol. 1999, 123, 607-612. [CrossRef]

16. Holler, T.C.; Peebles, M.; Young, A.; Whiteman, L.; Olson, S.; Sivinski, J. Efficacy of the Suterra biolure individual female fruit fly attractant packages vs. the unipak version. Fla. Entomol. 2009, 92, 667-669.

17. Navarro-Llopis, V.; Alfaro, F.; Domínguez, J.; Sanchis, J.; Primo, J. Evaluation of traps and lures for mass trapping of Mediterranean fruit fly in citrus groves. J. Econ. Entomol. 2008, 101, 126-131. [CrossRef] [PubMed]

18. Peñarrubia-María, I.E.; Quilici, S.; Schmitt, C.; Escudero-Colomar, L.A. Evaluation of candidate systems for mass trapping against Ceratitis spp. on La Réunion island. Pest Manag. Sci 2014, 70, 448-453. [CrossRef]

19. Broughton, S.; Rahman, T. Evaluation of lures and traps for male and female monitoring of Mediterranean fruit fly in pome and stone fruit. J. Appl. Entomol. 2017, 141, 441-449. [CrossRef]

20. Mavraganis, G. Maillard Reaction Products for Attracting Insects. Greece Patent. Inventor WO Patent 2012/056257, 3 May 2012.

21. Kouloussis, N.; Papadopoulos, N.; Ioannou, C.; Damos, P.; Koveos, D.; Bempelou, E.; Mavraganis, V. First results on mass trapping of Ceratitis capitata using the new attractant Biodelear. Iobc-Wprs Bull. 2017, 123, 39-42.

22. Til, H.; Falke, H.; Prinsen, M.; Willems, M. Acute and subacute toxicity of tyramine, spermidine, spermine, putrescine and cadaverine in rats. Food Chem. Toxicol. 1997, 35, 337-348. [CrossRef]

23. Wyatt, I.; Soames, A.; Clay, M.; Smith, L. The accumulation and localisation of putrescine, spermidine, spermine and paraquat in the rat lung: In vitro and in vivo studies. Biochem. Pharmacol. 1988, 37, 1909-1918. [CrossRef]

24. Cohen, H.; Yuval, B. Perimeter trapping strategy to reduce Mediterranean fruit fly (Diptera: Tephritidae) damage on different host species in Israel. J. Econ. Entomol. 2000, 93, 721-725. [CrossRef]

25. Hafsi, A.; Abbes, K.; Harbi, A.; Chermiti, B. Field efficacy of commercial food attractants for Ceratitis capitata (Diptera: Tephritidae) mass trapping and their impacts on non-target organisms in peach orchards. Crop Prot. 2020, 128, 104989. [CrossRef]

26. Martínez-Ferrer, M.; Navarro Campos, C.; Campos Rivela, J.M.; Marzal Moreno, C.; Fibla, J.; Bargues Desolmes, L.; García Mari, F. Seasonal and annual trends in field populations of Mediterranean fruit fly, Ceratitis capitata, in Mediterranean citrus groves: Comparison of two geographic areas in eastern Spain. Span. J. Agric. Res. 2010, 8, 757-765. [CrossRef]

27. Navarro-Llopis, V.; Primo, J.; Vacas, S. Bait station devices can improve mass trapping performance for the control of the Mediterranean fruit fly. Pest Manag. Sci. 2015, 71, 923-927. [CrossRef]

28. Hafsi, A.; Abbes, K.; Harbi, A.; Duyck, P.F.; Chermiti, B. Attract-and-kill systems efficiency against C eratitis capitata (D iptera: T ephritidae) and effects on non-target insects in peach orchards. J. Appl. Entomol. 2016, 140, 28-36. [CrossRef]

29. Miranda, M.; Alonso, R.; Alemany, A. Field evaluation of medfly (Dipt., Tephritidae) female attractants in a Mediterranean agrosystem (Balearic Islands, Spain). J. Appl. Entomol. 2001, 125, 333-339. [CrossRef]

30. Boller, E. Rhagoletis cerasi and Ceratitis capitata. Handb. Insect Rearing 1985, 2, 135-144.

31. Katsoyannos, B.I.; Papadopoulos, N.T. Evaluation of synthetic female attractants against Ceratitis capitata (Diptera: Tephritidae) in sticky coated spheres and McPhail type traps. J. Econ. Entomol. 2004, 97, 21-26. [CrossRef] [PubMed]

32. Economopoulos, A.P. Use of traps based on color and/or shape. In World Crop Pests, Fruit Flies, Their Biology, Natural Enemies and Control; Robinson, A.S., Hooper, G., Eds.; The Elsevier Science Publishers: Amsterdam, The Netherlands, 1989; Volume 3B, pp. 315-327.

33. Katsoyannos, B.I. Response to shape, size and color. In Fruit Flies: Their Biology, Natural Enemies and Control. World Crop Pests; Robinson, A.S., Hooper, G., Eds.; Elsevier: Amsterdam, The Netherlands, 1989; Volume 3A, pp. 307-324.

34. Alemany, A.; Alonso, D.; Miranda, M.A. Evaluation of improved Mediterranean fruit fly attractants and retention systems in the Balearic Islands (Spain). In Proceedings of the 6th International Symposium on Fruit Flies of Economic Importance, Stellenbosch, South Africa, 6-10 May 2002; Barnes, B.N., Ed.; Isteg Scientific Publications: lrene, South Africa, 2004; pp. 355-359.

35. Katsoyannos, B.; Papadopoulos, N.; Heath, R. Field evaluation of trap types and lures for Bactrocera oleae (Diptera: Tephritidae). Experiments conducted in Chios, Greece. In Proceedings of the a Final Research Coordination Meetingorganized by the Joint FAO/IAEA Programme of Nuclear Techniques in Food and Agriculture, Vienna, Austria, 5-7 May 2005; IAEA: Vienna, Austria, 2007; pp. 33-42.

36. Broughton, S.; De Lima, C.F. Field evaluation of female attractants for monitoring Ceratitis capitata (Diptera: Tephritidae) under a range of climatic conditions and population levels in Western Australia. J. Econ. Entomol. 2002, 95, 507-512. [CrossRef] 
37. Papadopoulos, N.T.; Katsoyannos, B.I.; Nestle, D. Spatial autocorrelation analysis of a Ceratitis capitata (Diptera: Tephritidae) adult population in a mixed deciduous fruit orchard in northern Greece. Environ. Entomol. 2003, 32, 319-326. [CrossRef]

38. Broughton, S.; Rahman, T.; Woods, B. Sustainable Management of Medfly without Cover Sprays, Project Number: MT12012; Horticulture Innovation Australia: Sydney, Australia, 2015; pp. 1-98.

39. Manrakhan, A.; Daneel, J.H.; Beck, R.; Virgilio, M.; Meganck, K.; De Meyer, M. Efficacy of trapping systems for monitoring of Afrotropical fruit flies. J. Appl. Entomol. 2017, 141, 825-840. [CrossRef]

40. Nakagawa, S.; Prokopy, R.J.; Wong, T.T.; Ziegler, J.R.; Mitchell, S.M.; Urago, T.; Harris, E.J. Visual orientation of Ceratitis capitata flies to fruit models. Entomol. Exp. Appl. 1978, 24, 193-198. [CrossRef]

41. Levinson, H.Z.; Levinson, A.R.; Müller, K. Influence of some olfactory and optical properties of fruits on host location by the Mediterranean fruit fly (Cera titis capita ta Wied.). J. Appl. Entomol. 1990, 109, 44-54. [CrossRef]

42. Katsoyannos, B. Effect of color properties of spheres on their attractiveness for Ceratitis capitata (Wiedemann) flies in the field. J. Appl. Entomol. 1987, 104, 79-85. [CrossRef]

43. Lance, D.; Gates, D. Sensitivity of detection trapping systems for Mediterranean fruit flies (Diptera: Tephritidae) in southern California. J. Econ. Entomol. 1994, 87, 1377-1383. [CrossRef]

44. Barclay, H.J.; Li, C. Combining methods of pest control: Minimizing cost during the control program. Theor. Popul. Biol. 1991, 40, 105-123. [CrossRef]

45. Navarro-Llopis, V.; Domínguez-Ruiz, J.; Zarzo, M.; Alfaro, C.; Primo, J. Mediterranean fruit fly suppression using chemosterilants for area wide integrated pest management. Pest Manag. Sci. Former. Pestic. Sci. 2010, 66, 511-519. [CrossRef]

46. Katsoyannos, B. Evaluation of Mediterranean fruit fly traps for use in sterile insect technique programmes. J. Appl. Entomol. 1994, 118, 442-452. [CrossRef]

47. Vargas, R.I.; Souder, S.K.; Rendon, P.; Mackey, B. Suppression of Mediterranean fruit fly (Diptera: Tephritidae) with trimedlure and biolure dispensers in Coffea arabica (Gentianales: Rubiaceae) in Hawaii. J. Econ. Entomol. 2018, 111, 293-297. [CrossRef]

48. El-Sayed, A.; Suckling, D.; Wearing, C.; Byers, J. Potential of mass trapping for long-term pest management and eradication of invasive species. J. Econ. Entomol. 2006, 99, 1550-1564. [CrossRef]

49. Martinez-Ferrer, M.; Campos, J.; Fibla, J. Field efficacy of Ceratitis capitata (Diptera: Tephritidae) mass trapping technique on clementine groves in Spain. J. Appl. Entomol. 2012, 136, 181-190. [CrossRef]

50. Rousse, P.; Duyck, P.F.; Quilici, S.; Ryckewaert, P. Adjustment of field cage methodology for testing food attractants for fruit flies (Diptera: Tephritidae). Ann. Entomol. Soc. Am. 2005, 98, 402-408. [CrossRef]

51. Lasa, R.; Velázquez, O.E.; Ortega, R.; Acosta, E. Efficacy of commercial traps and food odor attractants for mass trapping of Anastrepha ludens (Diptera: Tephritidae). J. Econ. Entomol. 2014, 107, 198-205. [CrossRef] [PubMed] 